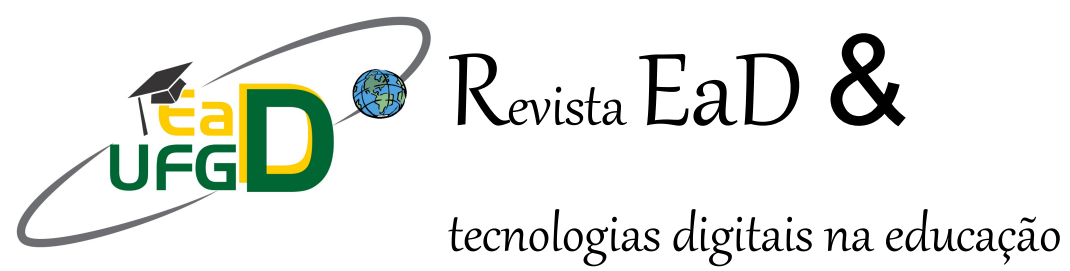

\title{
Glossário de Libras: caminhos para construção de instrumento de coleta de dados
}

\author{
Rosana de Fátima Janes Constâncio ${ }^{1}$, UFGD \\ Ana Paula Oliveira e Fernandes ${ }^{2}$, UFGD \\ Eliane Francisca Alves da Silva Ochiuto ${ }^{3}$, UFGD \\ Gabriele Cristine Rech ${ }^{4}$, UEMS
}

\begin{abstract}
Resumo: $O$ projeto aqui apresentado tem como premissa investigar, coletar, divulgar e propagar os sinais dos principais lugares públicos e pontos turísticos para viabilizar e socializar não somente a comunidade surda usuária da Libras, mas possibilitar a propagação a toda população da Grande Dourados os sinais específicos destes locais garantindo ao surdo o acesso e acessibilidade. Para a elaboração do glossário a proposta inicial foi de realizar uma pesquisa envolvendo a participação em formato de questionário aos tradutores intérpretes de língua de sinais, surdos usuários da Libras a fim de identificar os possiveis sinais já existentes, bem como o estudo e a criação de sinais que identifiquem tais pontos. A produção deste glossário corrobora para a criação e difusão de toda a história dos principais lugares públicos e pontos turísticos disseminando a cultura local e possibilitando o uso e a difusão da Libras conforme previsto na Lei de Libras.
\end{abstract}

Palavras-chave: Glossário, Lugares Públicos, Comunidade Surda.

\footnotetext{
${ }^{1}$ Mestre em Educação pelo Centro Universitário Moura Lacerda (CUML). Docente e coordenadora do curso de licenciatura Letras Libras da Faculdade a Distância da Universidade Federal da Grande Dourados (EaD/UFGD). Membro do grupo de Pesquisa GELES.

${ }^{2}$ Mestre em Linguística pela PPG/UFGD. Docente do curso de licenciatura Letras Libras da Faculdade a Distância da Universidade Federal da Grande Dourados (EaD/UFGD). Coordenadora Adjunta UAB/EaD/UFGD.

${ }^{3}$ Mestre em Letras- Estudos Linguísticos, pelo PPG/UFMS/ CPTL-. Docente do curso de licenciatura Letras Libras da Faculdade a Distância da Universidade Federal da Grande Dourados.

${ }^{4}$ Mestre em linguística pela Universidade Federal de Santa Catarina (UFSC). Docente da Universidade Estadual do Mato Grosso do Sul (UEMS), da disciplina de Libras nos cursos de pedagogia e licenciatura em matemática, química, física, ciências biológicas, enfermagem, letras/inglês e letras/espanhol.
} 


\section{Introdução}

O reconhecimento da Libras como meio legal de comunicação e expressão possibilitou uma comunicação efetiva para oriundos de comunidade surda e seus usuários no ano de 2002 através da Lei Federal no 10.436/02. No ano de 2005 o Decreto no 5626/05 regulamentou esta Lei garantindo assim o uso e difusão da mesma.

Diante dos fatos, várias ações em todo território nacional, estão sendo construídas no sentido de coletar, registrar e disponibilizar para os usuários da Libras os sinais existentes e utilizados para designar diversas categorias. O projeto aqui apresentado caminha nesta direção. Tendo como recorte geográfico a cidade de Dourados, tendo como objetivos: 1) investigar os sinais já utilizados pela comunidade surda local para nomear os principais locais públicos, pontos turísticos e as cidades próximas; 2) criar, juntamente com os surdos informantes, sinais inexistentes para algumas localizações; 3 ) registrar por meio de um glossário os sinais coletados/criados e 4) disponibilizar o glossário de forma on-line.

Registramos inicialmente o resultado apenas de um dos objetivos que é o da coleta de dados, pois o presente artigo apresenta os dados de um projeto que está em andamento e que constatou a necessidade de criação de um instrumento padronizado para esta coleta.

O referido projeto surgiu através de conversas informais entre os professores da Faculdade de Educação a Distância da UFGD (Universidade Federal da Grande Dourados), e da UEMS (Universidade Estadual do Mato Grosso do Sul), que apontaram preocupação do registro dos sinais da região como instrumento de preservação, valorização e conhecimento da Língua Brasileira de Sinais. Segundo Souza Júnior:

A ação de nomear um lugar projeta a visão de mundo de uma comunidade e revela traços naturais ou culturais a ela pertencentes. Desse modo, a nomeação dos lugares e do nome das pessoas dada pelo ser humano comporta aspectos relevantes a serem considerados nos estudos da linguagem. (2015, p. 211):

O glossário viabilizará vencer as barreiras de comunicação que é um dos entraves linguísticos na comunicação entre surdos e ouvintes. A elaboração do glossário não se restringe apenas a criar novos sinais, mas possibilitar a imersão na cultura local, na valorização do sujeito surdo em sua especificidade linguística, na criação de um portal que de fato garanta a acessibilidade conforme preconiza a Lei no $13.146 / 15$, no artigo 3으, item III.

Tecnologia assistiva ou ajuda técnica: produtos, equipamentos, dispositivos, recursos, metodologias, estratégias, práticas e serviços que objetivem promover a funcionalidade, relativa à atividade e à participação da pessoa com deficiência ou com mobilidade reduzida, visando à sua autonomia, independência, qualidade de vida e inclusão social. (BRASIL, 2015)

Após algumas reuniões, a equipe decidiu que iniciaria a coleta dos sinais da categoria "FACULDADES/UNIVERSIDADES" e "SUPERMERCADOS". A escolha dessas categorias para iniciar o projeto deu-se em virtude da hipótese da existência de muitos sinais 
para designar os locais, sendo mais fácil testar o instrumento elaborado pelas pesquisadoras, conforme descreveremos abaixo.

A hipótese inicial era de registrar os sinais dos locais apresentados para a comunidade surda, mas durante a aplicação do instrumento de pesquisa, foi possível constatar certa dificuldade para compreender a forma que estava sendo aplicado por parte dos participantes quando apresentamos os locais referentes à categoria supermercados.

Assim, justifica-se a importância do presente projeto de pesquisa, por esse - o glossário- vir a ser um meio de corroborar com mudanças de paradigmas e dissipar estigmas fortemente arraigados em uma cultura que preconiza a perfeição como meio de valorização do ser humano, pois esta iniciativa atenderá surdos e ouvintes, pesquisadores, tradutores e intérpretes de Libras, comunidade leiga e profissional, viabilizando a comunicação favorecendo a inclusão.

\section{Metodologia}

Após a decisão das categorias a serem analisadas, o próximo passo foi a elaboração do instrumento de coleta de dados a ser adotado. Devido a carência de publicações na área, não foi possível localizar instrumentos de coletas de dados em pesquisas semeIhantes para servir de modelo e base para nortear o trabalho proposto, assim, através de discussões em grupo, decidimos elaborar um instrumento para a coleta dos dados, como teste.

Num primeiro momento, foi feito uma relação das faculdades/universidades e dos supermercados mais conhecidos da cidade. A segunda etapa constituiu em verificar os sinais já conhecidos pelas pesquisadoras para designar cada local e pôr fim a elaboração do instrumento em si.

Foi decidido que as pesquisadoras surdas fariam as filmagens dos sinais já conhecidos, que seriam apresentados aos entrevistados, que por sua vez, após assistirem cada vídeo, marcariam um (x) no "sim", caso conhecessem o sinal apresentado e um (x) o não, caso "não" conhecessem o sinal apresentado. O questionário estava estruturado levando em conta os nomes e logomarcas das empresas, conforme figura a seguir: 
PROJETO GLOSSARIO DE UIFAS DA GRANDE DOURADOS

BESPOSTAS QUESTIDNAFIO SMAS

FACULDADES E LINERSIDADES

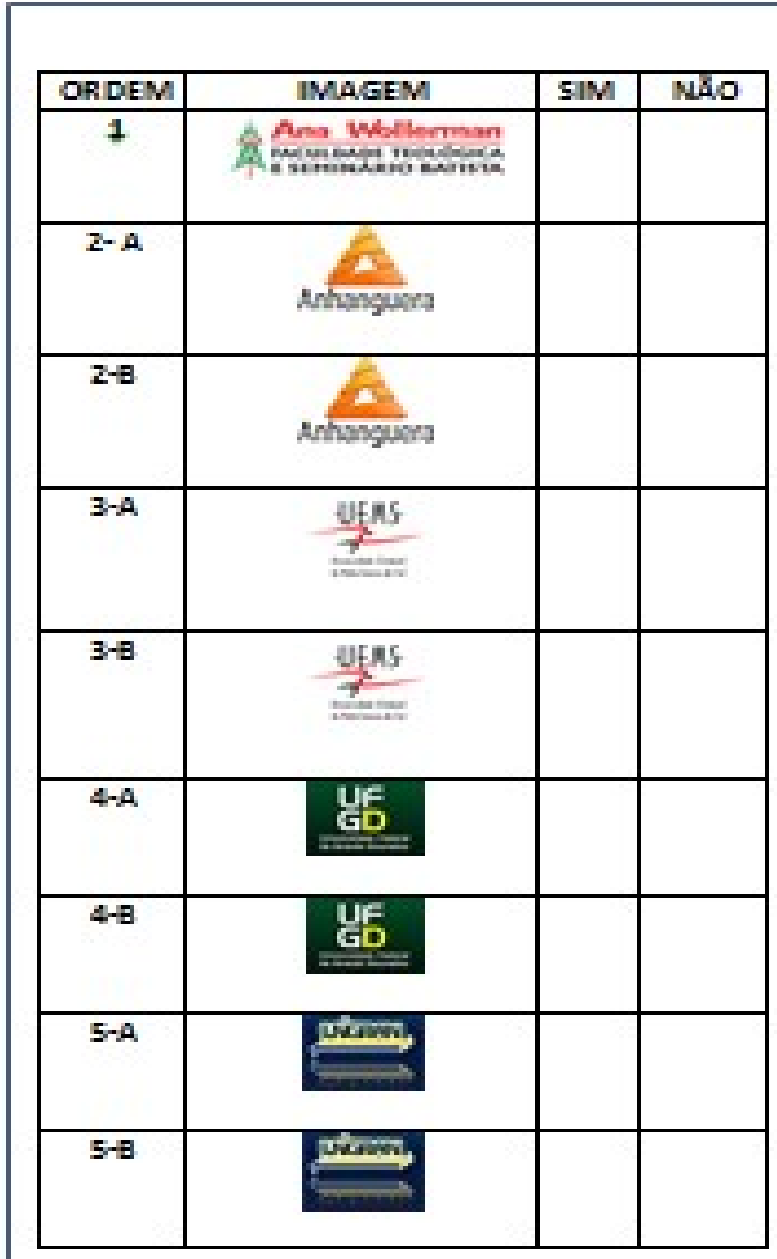

SUPEFMERCAL

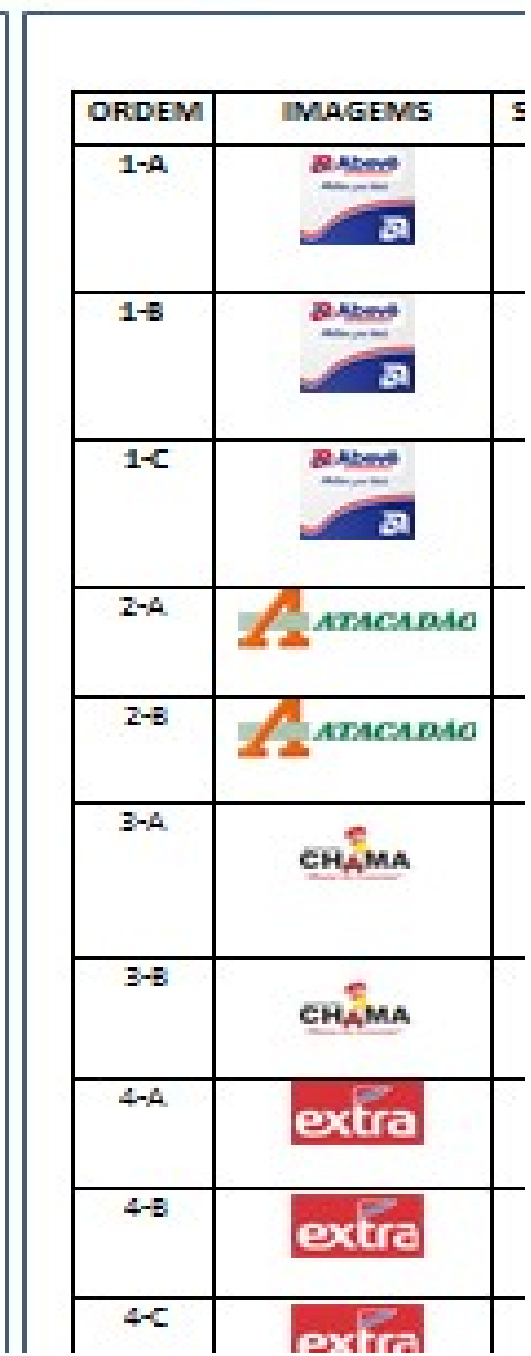

Figura 1 - modelo de questionário elaborado para respostas sobre os sinais

Cientes que, em diversos momentos, a comunidade surda utiliza do alfabeto manual para designar vocábulos que ainda não possuem sinais, foi decidido que, para cada vocábulo dos locais pesquisados, seria apresentado primeiro o nome soletrado (Letra A quando o vocábulo tem mais de um sinal) e após, o(s) sinai(s) conhecidos para que os informantes assinalassem o(s) que era $(\mathrm{m})$ conhecido(s) por eles. Apresentamos, como exemplo, as opções de sinais para representar o vocábulo ABEVE, um grande supermercado da cidade. 


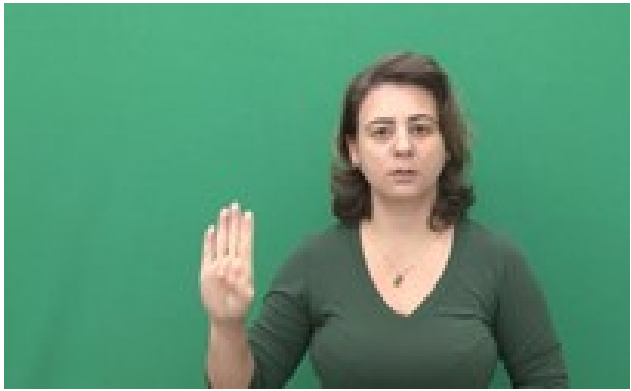

Soletração de ABEVE

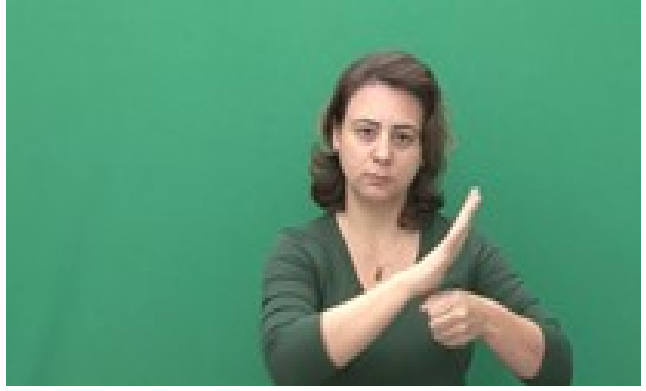

Sinal ABEVE (1)

Sinal ABEVE (2)

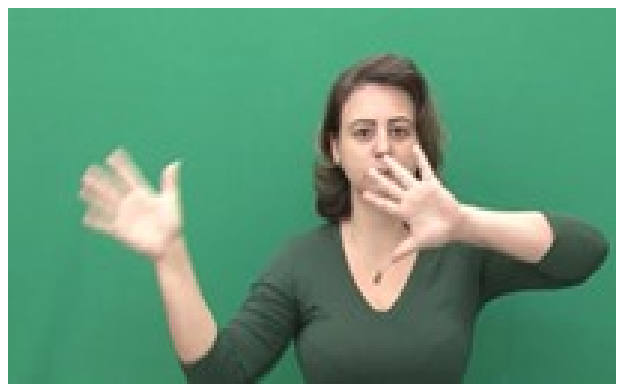

\section{Figura 2 - sinais utilizados para conhecimento e resposta ao questionário}

Após a confecção do instrumento de pesquisa, foi elaborado um cartão que foi entregue para diversos surdos da cidade, convidando-os para a reunião presencial, que aconteceria nas dependências da Faculdade de Educação a Distância e da Universidade Federal Mato Grosso do Sul. A escolha do local deu-se pela centralidade do prédio, de fácil acesso.

Importante ressaltar que ficou decidido, que num primeiro momento, os entrevistados seriam todos surdos, por serem usuários nativos da língua. Mediante autorização escrita de todos os entrevistados, a reunião toda foi filmada, procurando registrar todos os momentos de discussões. Os equipamentos utilizados, para coletar e registrar os sinais, num primeiro momento, são os de uso pessoal das pesquisadoras.

Compareceram a primeira reunião dezessete surdos (as), sendo nove mulheres e oito homens, na faixa etária dos dezenove aos quarenta e quatro anos que na sua maioria residem em Dourados há mais de dez anos.

Logo após a apresentação detalhada de toda pesquisa, os entrevistados preencheram o Termo de Consentimento Livre e Esclarecido, os vídeos foram apresentados com as imagens alvo da pesquisa no momento e a coleta das informações objetivadas neste projeto possibilitou diagnosticar quais sinais são utilizados pelos surdos douradenses para estes respectivos locais apresentados.

A cada vídeo, a pesquisadora surda perguntava "VOCÊ CONHECER? (Apontar para o sinal exibido no vídeo). Os entrevistados, em alguns momentos apenas respondiam e em muitos discutiam os sinais apresentados. Entretanto, uma questão nos chamou atenção: Os entrevistados estavam relacionando o "CONHECER" no sentido de apenas conhecer o lugar, ou estavam atribuindo ao "CONHECER" o sentido de conhecer o sinal e utilizá-lo?

Intuitivamente, durante a aplicação da segunda parte do "questionário", as pesquisadoras perceberam que poderiam estar confundindo os entrevistados com o uso do termo "CONHECER", e começaram a utilizar a seguinte sentença para coletar os dados 
desejados: 'VOCÊ USAR SINAL? OU SOLETRAÇÃO/DATILOLOGIA? (Apontava para o sinal exibido no vídeo).

Após a coleta, o próximo passo foi a analisar os dados obtidos. As análises dos dados coletados serão realizadas em triangulação, comparando-se dados e informações obtidas nas mencionadas fontes, relacionando-as com o referencial teórico e as questões de pesquisa (TRIVINOS, 1987). Na análise, processaremos e armazenaremos todas as informações observadas, ouvidas e lidas para depois tentar atribuir-lhes significado, buscando uma representação mental significativa de acontecimentos reais e eventos discursivos, a partir de um conhecimento mais geral a respeito de acontecimentos e ações comuns com as quais tínhamos envolvimento direto, antes do início da pesquisa.

Além da identificação dos sinais utilizados pelos sujeitos surdos para serem registrados e inseridos no glossário que será construído, foi realizada a análise das respostas para verificar se a questão de a mudança do termo "CONHECER" para "USAR", teve influência nos resultados e decidir, caso positivo, o procedimento para averiguar dados mais "puros".

A detecção de que o vocábulo poderia estar sendo compreendido de forma diferente da desejada pelas pesquisadoras aconteceu quando a pesquisa já estava analisando os sinais da categoria "supermercado", especificamente o sinal referente ao supermercado "Atacadão". Abaixo o quadro que compila todos os dados:

PFOUET GLOSSAFIO DE UAFAS DA GRANDE DQUFADDS

RESPRETAS QLESTIOMURID SMLE
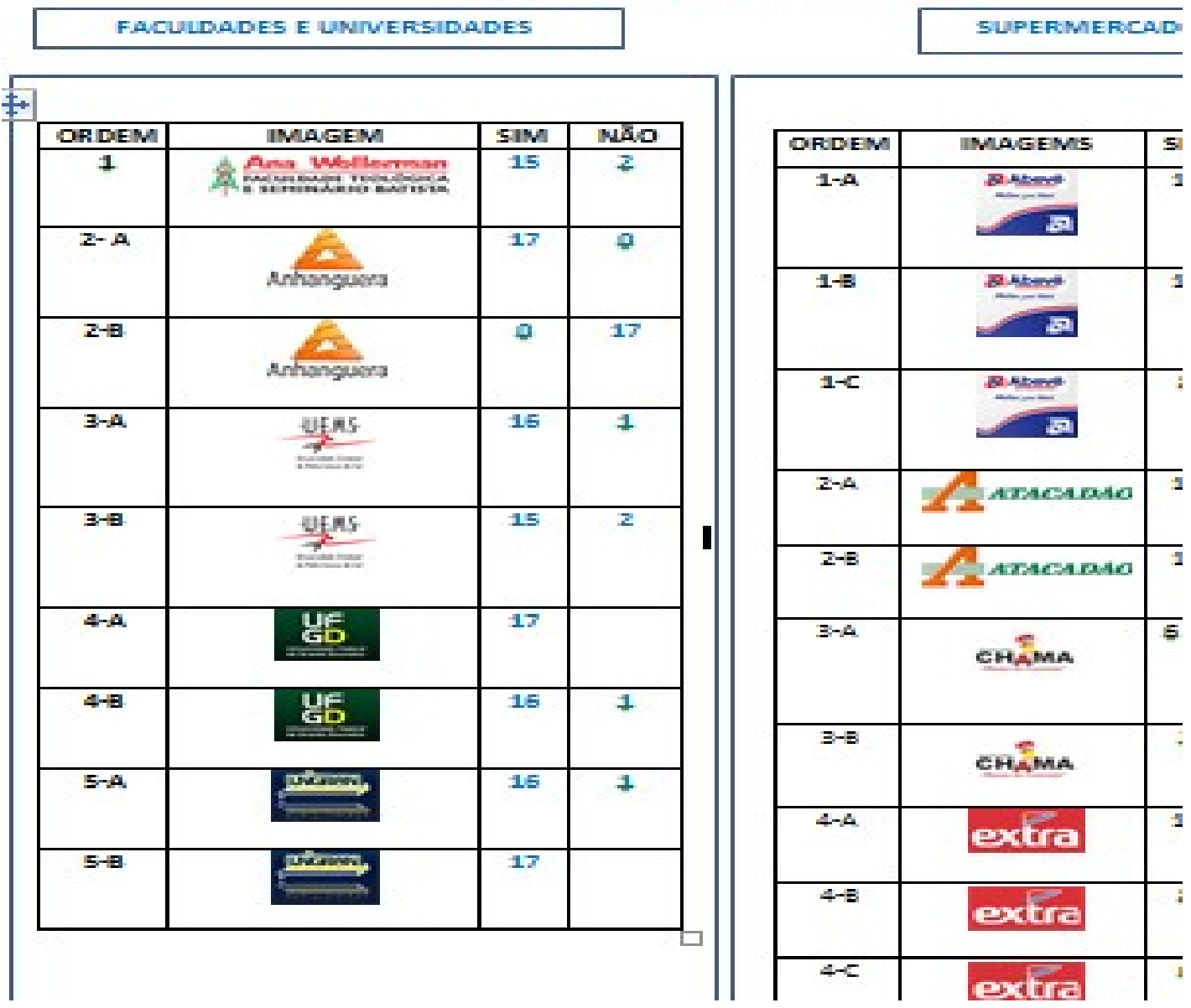

Figura 3 - Respostas realizadas pelos surdos 
Conforme exposto acima, quando os vocábulos apresentam mais de uma sugestão de sinal, a letra A foi destinada a designação dos sinais que foram feitos com o empréstimo do alfabeto manual. Neste sentido, é notório que até o sinal do vocábulo "Atacadão", praticamente todas as letras A tem grande incidência de sinalização positiva para o "conhecimento" do que foi apresentado no vídeo. A partir do supermercado "Chama" percebe-se uma diminuição na frequência das sinalizações pelo "USO" do termo apresentado no vídeo.

\section{Resultados e discussão}

O glossário tem sido considerado um recurso relevante para a sociedade como estratégia de adquirir conhecimento de mundo, ampliando o vocabulário da língua em uso seja ela oral/auditiva ou em Língua de Sinais.

A partir das primeiras experiências vivenciadas na aplicação da coleta de dados, e do contato com a comunidade surda participante do projeto, e discussões plausíveis a respeito dos sinais referentes às categorias UNIVERSIDADES/FACULDADES e SUPERMERCADOS, observamos pontos importantes para enfatizar a relevância do projeto, tais como:

- O mesmo contribuirá para registrar e disseminar a cultura local possibilitando ao surdo conhecer e assimilar os sinais aos locais;

- Possibilitará aos ouvintes aprender os sinais específicos dos locais a fim de que possam se apropriar de uma língua e cultura com singularidades e especificidades próprias do jeito de ser e de compreender o mundo surdo.

- Ampliar o campo de aquisição de língua de sinais por parte dos pesquisadores como também dos participantes do mesmo, como forma de fortalecer a língua enriquecendo os discursos com sinais que respeite a cultura local.

- Por ser projeto pioneiro na região da Grande Dourados, no que se diz respeito à língua de sinais, buscando um estudo sistemático dos signos linguísticos referente aos pontos turísticos, bem como no seu registro, permitirá que a comunidade surda douradense e região tenha sua cultura preservada por meio do registro da Libras no Glossário especifico para a região.

Diante das primeiras experiências e das observações positivas em relação ao projeto, também pudemos repensar nossa estratégia de aplicação do instrumento de coleta de dados, a partir do momento que identificamos uma falha no questionamento de que os participantes conheciam o sinal realizado pela pesquisadora surda. Portanto, após discussões pós encontro com a comunidade surda, que faz parte da pesquisa, decidimos modificar a estratégia de aplicação dos questionários para a coleta de dados, ficando assim, que para próximos encontros ,e ainda em fase de teste, não mais apresentaríamos os sinais das categorias que vierem a serem pesquisadas os sinais, mas sim apresentaremos os nomes e imagens, e os surdos fariam os sinais que conhecem e enumeraremos os mesmos, assim os demais assinalará aquele o qual faz uso diariamente.

Enfim, com todas as discussões, pretende-se, além da sistematização e das produções científicas/bibliográficas que serão elaboradas, contribuir para o ensino da língua de sinais tanto nos cursos de Libras oferecidos, ou seja, ensino de Libras como segunda língua, quanto no ensino das crianças surdas em sala de aula, onde aprendem Língua de Sinais como primeira língua, pois o glossário, poderá ser acessado e explorado em ambos os casos. 


\section{Referências}

BRASIL. Lei №. 10.436 de 20 de abril de 2002. Dispõe sobre a Língua Brasileira de Sinais. Brasília: Presidência da República, Casa Civil, 2002.

BRASIL. Decreto №. 5.626 de 22 de dezembro de 2005. Regulamenta a Lei no 10.436/02. Brasília: Presidência da República, Casa Civil, 2005.

BRASIL. Lei no 13.146 de 06 de julho de 2015. Lei Brasileira de Inclusão da Pessoa com Deficiência (Estatuto da Pessoa com Deficiência). Brasília: Presidência da República, Casa Civil, 2015.

SOUZA-JÚNIOR, J. E. G de. Estudos introdutórios da Toponímia da Língua de Sinais Brasileira - LSB In: BRUNO, M. M. G; OLIVEIRA, O. V; Organizadoras. Educação escolar indígena, diferença e deficiência: (re)pensando práticas pedagógicas. Campo Grande, MS: Ed. UFMS, 2015.

TRIVIÑOS, A. S. Introdução à pesquisa em ciências sociais: A pesquisa qualitativa em educação. São Paulo: Atlas, 1987. 